\title{
Climate mitigation. Is it possible via DSS for agriculture? A case study: Reducing the Environmental Footprint of cotton cultivation
}

\author{
Dimitrios Leonidakis', Nikolaos Katsenios², Panagiotis Sparangis², Christoforos Nikitas Kasimatis², Dimitrios \\ Vlachakis ${ }^{3,4,5}$, Aspasia Efthimiadou ${ }^{2 \bowtie}$
}

\author{
${ }^{1}$ Farmacon G.P., K. Therimioti 25, Giannouli, Larisa, 41500 Thessaly, Greece \\ ${ }^{2}$ Department of Soil Science of Athens, Institute of Soil and Water Resources, Hellenic Agricultural Organization-Demeter, Sofokli \\ Venizelou 1, Lycovrissi, 14123 Attica, Greece \\ ${ }^{3}$ Laboratory of Genetics, Department of Biotechnology, School of Applied Biology and Biotechnology, Agricultural University of \\ Athens, 11855 Athens, Greece \\ ${ }^{4}$ Lab of Molecular Endocrinology, Center of Clinical, Experimental Surgery and Translational Research, Biomedical Research \\ Foundation of the Academy of Athens, 11527 Athens, Greece \\ ${ }^{5}$ Department of Informatics, Faculty of Natural \& Mathematical Sciences, King's College London, London, United Kingdom \\ Competing interests: DL none; NK none; PS none; CNK none; DV none; AE none
}

Cotton is a very important industrial cultivation in Greece and all over the world. The main issue regarding the cultivation of cotton is irrigation because it is strictly water-dependent (Dağdelen et al., 2006). This means that the costs and the environmental footprint are high.

However, recent research indicated that the amounts of water that are used for irrigation could be reduced. The technological evolution has made Neural Network based Decision Support Systems, combined with data analysis, to be considered the future of sustainable agriculture. Cotton growers need to adopt new technologies not only to increase production but also to reduce water needs. The development of an innovative cotton production support system was conducted, consisting of five different types of measurements. Data from IoT sensors, weather stations, remote sensing data (Sentinel 2 images), soil analysis and on-site measurements (yield and EM38) derived from five experimental fields in Greece, creating a dataset of thirteen different inputs. A total of thirteen different algorithms were put into the test and evaluated to find the best one in terms of time and efficiency. In this research, we implemented a Decision Support System to assess the true water need of cotton cultivation (Salinari et al., 2014).

\section{References}

1. Dağdelen N, Yılmaz E, Sezgin F, Gürbüz T (2006) Water-yield relation and water use efficiency of cotton (Gossypium hirsutum L.) and second crop corn (Zea mays L.) in western Turkey. Agricultural Water Management 82(1):63-85. http://dx.doi. org/10.1016/j.agwat.2005.05.006

2. Salinari F, Mariani L, Poni S, Cola G, Bettati T et al. (2014) Development of a water stress alert system embedded in a DSS for Integrated Vineyard Management. Acta Horticulturae 1038:565572. http://dx.doi.org/10.17660/ActaHortic.2014.1038.71 